\title{
Study on Coal Moisture Control Technology Using Superheated Steam Zhong-Hua WU ${ }^{1}$, Bing LIU ${ }^{1}$, Jian-Shu YIN $^{1}$, Ning KANG ${ }^{1}$ and Li-Juan $\mathrm{ZHAO}{ }^{1,2, *}$ \\ ${ }^{1}$ College of Mechanical Engineering ,Tianjin University of Science and Technology, Tianjin,China 300222; \\ ${ }^{2}$ Tianjin Key Laboratory of Integrated Design and On-line Monitoring for Light Industry \& Food Machinery and Equipment, Tianjin,China 300222;
}

*Tel: 022-60600708; E-mail: zhaolj@tust.edu.cn

\section{Keywords: Coking coal; Superheated steam; Coal moisture control}

\begin{abstract}
To avoid the fire and explosion danger in the current coking coal moisture control technology, a new coal moisture control technology was proposed in this paper where the superheated steam was used as the drying medium. A self-developed lab scale superheated steam drying experimental setup was constructed and the coal moisture control experiments were carried out. Experimental results showed that the superheated steam can be used as drying medium to reduce the coal moisture from initial $11.9 \%$ into the required $6 \%$ successfully. Super heated steam temperature,the thickness of coking coal are the key governing parameter in the drying process. Under this experimental condition,when super heated steam temperature increased from $130^{\circ} \mathrm{C}$ to $190^{\circ} \mathrm{C}$, the drying time of coking coal was shortened from $6 \mathrm{~min}$ to only $1.5 \mathrm{~min}$. The superheated steam was promising for developing a fast, energy saving coking coal moisture control technology.
\end{abstract}

\section{Introduction}

The coking coal used in the coking plants of China is usually washed coal, and its moisture content was usually $9 \%-12 \%$. The coking coal with a high moisture content will carry a mount of water into the coke oven. This water will evaporate into vapor during the coking process in the coke oven and finally form into harmful waste water,which needs to be treated. Furthermore, the evaporation of moisture during the coking process will consume some energy which used for coal coking, resulting a increasing amount and cost of coking gas. These problems require the coking plants to reduce the moisture content of the coking coal before coking and such technology is called as "coal moisture control" . The coal moisture control is the abbreviation of "water control process for loading coal",which mostly use the waste heat from the coking plant, such as high-temperature flue gas to heated the coal to remove its part of the moisture, so as to keep the moisture content of the coal at about $6 \%$ before the furnace is installed[1-3].

The current coal moisture control technology generally use the flue gas as the drying medium. Since the flue gas comprise the oxygen and the dried coal particle easily form dust. Thus the fire and explosion danger exist when using the flue gas. To avoid this problem, a new coal moisture control technology was proposed where the inert superheated steam was used as the drying medium to dry the coking coal into the required moisture content. The superheated steam was already used for drying of timber, foodstuffs, biomass, etc and its merits reported includes remarkable energy saving effect, good drying quality, high heat and mass transfer efficiency, no fire and explosion hazard[4-10].

In this paper, the superheated steam moisture control technology was developed for the coking coal where super heated steam was used as a heat medium to control moisture of coking coal into about 6\%. A series of drying experiments were conduced to study the temperature and pressure of super heated steam, its velocity, the thickness of coking coal,etc on the drying process of the moist coking coal. The experimental results increase the knowledge of the super heated steam coking coal moisture control technology. 


\section{Experiments and Methodology}

\section{Materials}

The coking coal used in these experiments was obtained at Jiangxi Fengcheng coking plant, Fengcheng, China. The coking coal was mixed by metabituminous and gas coal according to a certain proportion. The initial moisture content of coking coal was measured by drying oven method to be $11.9 \%$. The industry analysis was conducted by a professional coal testing center (Coal science (Tianjin) coal testing Co., Ltd.) testing. The testing results showed that the dry coking coal contains $0.64 \%$ of the total water, $10.16 \%$ ash, $25.99 \%$ volatile, $63.21 \%$ fixed carbon and $0.76 \%$ total sulfur.

\section{Apparatus}

Figure 1 showed the diagram of the self-developed super heated steam coking coal drying device. In Figure 1, steam generator produces saturated steam and a flow was used control the flow of steam. The saturated steam was heated by a heater into the super heated steam with the preset temperature. A certain mount of moist coking coal was holding into the drying chamber and took out for weighting at the certain drying time.

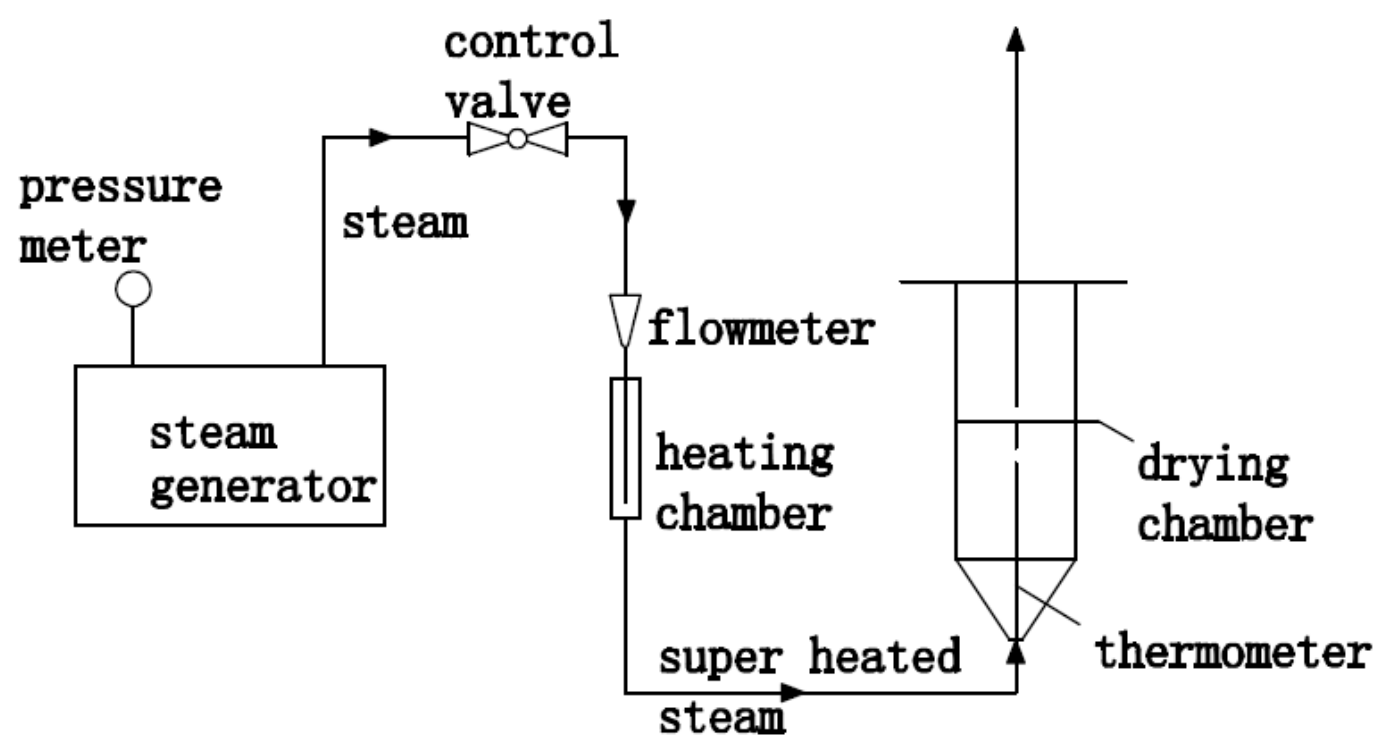

Fig. 1 Process Flow Diagram of Coal Moisture Control by Super heated Steam

\section{Procedure}

In the superheated steam coking coal drying experiments, the velocity, temperature of the super heated steam, the coal thickness were pre-set. During the drying process, the material was took out for weighing quickly, and then put back into the drying chamber at every 1 minutes until the weight is no longer changed. By plotting the coking weight with the drying time, the drying characteristic curves were obtained.

\section{Results and Discussion}

\section{Effect of Superheated Steam Temperature}

Figure 2 showed the drying curves of the coking coal at the drying conditions: the thickness of the coking coal was $40 \mathrm{~mm}$, steam flow $9 \mathrm{~kg} /$ hours, the drying temperatures are 130, 160, 190 OC respectively. These curves in Figure 2 show the drying is the fall drying rate process which can be divided three stages; the initial heating stage, the fast drying stage and consequent slow drying stage. In the case of $130^{\circ} \mathrm{C}$, a clear increase of the moisture content was observed in the initial heating 
stage. This can be explained that the initial material temperature was room one and when it entry the drying chamber. Since the initial coal temperature was lower than the one of super heated steam, the super heated steam at the coal surface will condensed into water and thus, increase the moisture content of the coking coal. The rise of the coaking coal moisture content at the initial heating stage reduces with the increased superheated steam temperature. In Figure 2, it was found that the higher the super heated steam temperature is,the shorter of the time that the moisture content of coking coal reaches $6 \%$. When the super heated steam temperature was $130^{\circ} \mathrm{C}, 160^{\circ} \mathrm{C}$ and $190^{\circ} \mathrm{C}$, the time that the moisture content of coking coal reaches $6 \%$ was $6 \mathrm{~min}$, $5 \mathrm{~min}$ and $1.5 \mathrm{~min}$ respectively. When the drying process reaches $10 \mathrm{~min}$, the moisture content of the material can be reduced to less than $2 \%$.

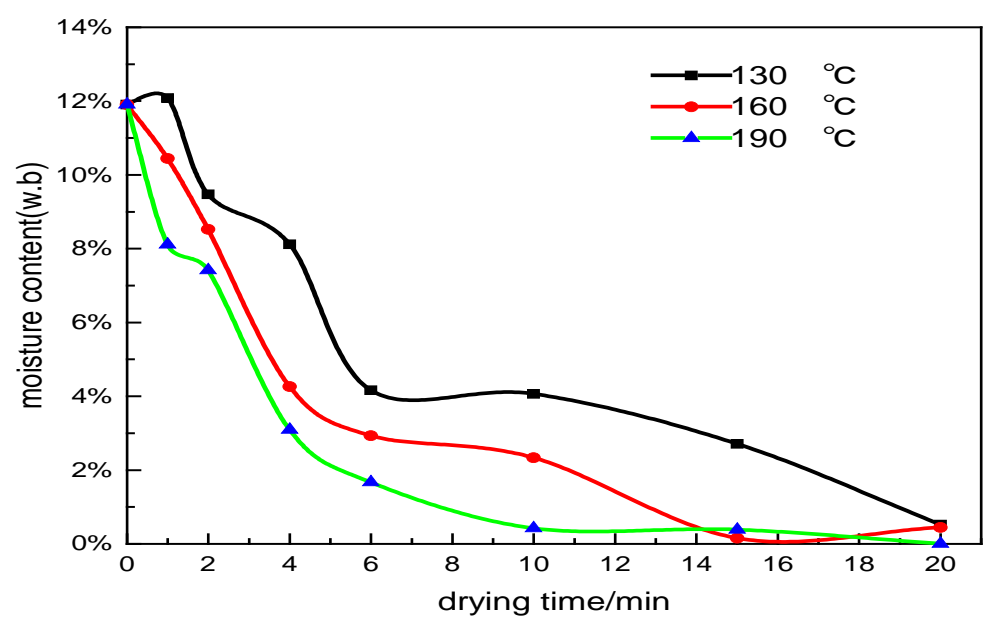

Fig. 2 Coking Coal Super Heated Steam Drying Curve (Coking Coal Thickness 40mm, Steam Flow $9 \mathrm{~kg} /$ hours)

\section{Effect of Coking Coal Thickness}

Figure 3 showed the drying curves of the coking coal at the different coal thickness when steam flow was kept at $9 \mathrm{~kg}$ / hours and the drying temperature at $160^{\circ} \mathrm{C}$. The obvious increase of coking coal moisture content were observed at the first initial heating stage. The rise of coal moisture content increase with the coal thickness. When the super heated steam temperature is $160^{\circ} \mathrm{C}$, the steam flow rate is $9 \mathrm{~kg} / \mathrm{h}$, and the material thickness is $40 \mathrm{~mm}, 80 \mathrm{~mm}$ and $160 \mathrm{~mm}$, the time that the moisture content of the coking coal was reduced to $6 \%$ is respectively $5 \mathrm{~min}, 9 \mathrm{~min}$ and $17 \mathrm{~min}$. When the drying process reaches $20 \mathrm{~min}$, the moisture content of the material can be reduced to less than $2 \%$. 


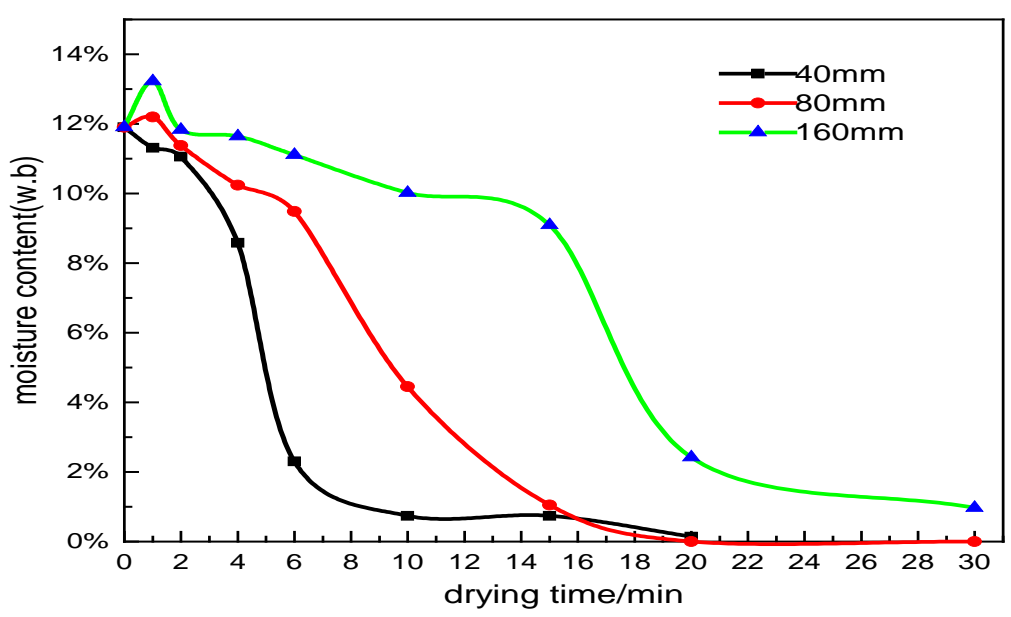

Fig. 3 Coking Coal Super Heated Steam Drying Curve (Steam Temperature $160{ }^{\circ} \mathrm{C}$, Steam Flow: $9 \mathrm{~kg} /$ hours)

\section{Conclusion}

This paper carried out the superheated steam moisture control experiments and the following conclusions were obtained from the experimental results.

1) Superheated steam can be used as a efficient drying medium for coal moisture control technology. In the experiments, the coking coal moisture content was reduced from its initial $11.9 \%$ into $5 \%$ in several minutes successfully.

2) The superheated drying process of coking coal comprise of the initial heating stage, fast drying rate and final slow drying rate stage. In the initial heating stage, the wetting phenomenon occurred easily.

3) The temperature of superheated steam and coal thickness were two important parameters in the coal moisture control technology.Under the experimental conditions, the temperature of super heated steam is from $130^{\circ} \mathrm{C}$ to $190^{\circ} \mathrm{C}$, the time that the moisture content of coking coal is reduced from $12 \%$ to $6 \%$ is from $6 \mathrm{~min}$ to $1.5 \mathrm{~min}$,indicating a fast coal moisture control process.

Furthermore experiments are being conducted to develop the superheated steam moisture control technology.

\section{Acknowledgement}

This research project was supported by China National Science Fund (Project Num: 31471618)

\section{Reference}

[1] A Furusawa, T Nakagawa ,T Maeno, I Komaki. Influence of Coal Moisture Control on Carbon Deposition in the Coke Oven Chamber. ISIJ International , 2007 , 38 (12) :1320-1325.

[2] P Cui , K L Qu, Q Ling, L Y Cheng, Y P Cao. Effects of coal moisture control and coal briquette technology on structure and reactivity of cokes. Coke \& Chemistry , 2015 , 58 (5) :162169 .

[3] S Wakuri , M Ohno, K Hosokawa , K Nakagawa, Y Takanohashi .New moisture control system of coal for coking. Transactions of the Iron \& Steel Institute of Japan, 2006 , 25 (11) :11111115 .

[4] R.G.Moreira Impingement drying of foods using hot air and superheated steam. Journal of Food 
Engineering.2001,49(4):291-295.

[5] C Moyne, D Stemmelen, A Degiovanni. A symmetric drying of porous materials at high temperature:theoretical analysis and experiments. International Chemical Engineering,1990,30(4):2725-2746.

[6] S Soponronnarit. A Comparative Study of Low-Pressure Superheated Steam and Vacuum Drying of a Heat-Sensitive Material. Drying Technology, 2004 , 22 (8) :1845-1867

[7] Z Tang.,S Cenkowski.Dehydration dynamics of potatoes in superheated steam and hot air. Canadian Agricultural Engineering, 2000, 42(1):43-49.

[8] C Henk van Deventer, Ruud M. H. Heijmans. Drying with superheated steam . Drying Technology,2001,19(8):2033-2045.

[9] C Nimmol , S Devahastin , T Swasdisevi ,S Soponronnarit . Drying of banana slices using combined low-pressure superheated steam and far-infrared radiation. Journal of Food Engineering , 2007 ,81 (3) :624-633

[10] F Karim.Applications of superheated steam for the drying of food products.International Agrophysics,2010,24(2):195-204. 